\title{
TABLI: PROTÓTIPO DE APLICATIVO GAMIFICADO PARA A CONSTRUÇÃO DE TESAUROS
}

\section{TABLI: PROTOTYPING OF A GAME APPLICATION TO THE THESAURUS CONSTRUCTION}

\author{
Dayanne Albuquerque Araújoa \\ Heliomar Cavati Sobrinho ${ }^{b}$
}

\begin{abstract}
RESUMO
Introdução: Esta pesquisa apresenta como tema a utilização de tecnologias digitais e da gamificação na disciplina Linguagens Documentárias (LD), devido à carência de uma plataforma direcionada ao ensino de construção de vocabulários, nesta disciplina, que atendam à realidade com o uso de tecnologias educacionais como ferramentas para a aprendizagem. Em razão das características atuais dos estudantes com o uso das plataformas móveis, a gamificação em ambientes digitais educativos torna o processo interativo, intuitivo e motivador em virtude de suas estratégias metodológicas. Objetivo: Propor uma ferramenta digital, por meio de um aplicativo gamificado, para o ensino da disciplina LDA. Metodologia: Utiliza o "Modelo metodológico integrado para construção de tesauros" (CERVANTES, 2009), da análise de Conteúdo (BARDIN, 2011) para os elementos da gamificação e da prototipação (PRESSMAN, 2006) para a construção do protótipo do aplicativo. Resultado: Desenvolvimento do protótipo do aplicativo nomeado "Tabli" com elementos da gamificação para a construção de tesauros. Conclusão: Há necessidade de dar continuidade ao desenvolvimento do aplicativo "Tabli", que poderá ser aplicável às dinâmicas atuais da sociedade que demandam metodologias tanto alternativas quanto inclusivas por meio da acessibilidade, para potencializar o ensino e aprendizagem na construção de tesauros, pois acredita-se que agregar o modelo de Cervantes (2009) à tecnologia móvel traga as vantagens de automação do processo, bem como a motivação e engajamento dos alunos, além de ser uma forma interativa e inovadora de aplicação para a área de Organização e Representação do Conhecimento.
\end{abstract}

Descritores: Representação da informação. Construção de tesauros. Tecnologia da informação. Aplicativos móveis. Gamificação. Plataformas digitais.

\footnotetext{
a Mestre em Ciência da Informação pelo Programa de Ciência da Informação da Universidade Federal do Ceará (UFC). E-mail: dayanneaaaraujo@gmail.com

b Doutor em Ciência da Informação pela Universidade Estadual Paulista Júlio de Mesquita Filho (UNESP). Docente do Departamento de Ciências da Informação e do Programa de Ciência da Informação da Universidade Federal do Ceará (UFC). E-mail: heliomarcavati@yahoo.com.br
} 


\section{INTRODUÇÃO}

Este artigo trata da utilização de tecnologias digitais e da gamificação na disciplina de Linguagens Documentárias Alfabéticas (LDA), ministrada no curso de Biblioteconomia da Universidade Federal do Ceará (UFC). Sendo a gamificação a "aplicação de mecanismos de jogos para a resolução de problemas, para a motivação e o engajamento de um determinado público". (VIANNA et al., 2013). Desenvolve-se uma ferramenta digital, por meio de um aplicativo gamificado, para a aplicação no ensino da disciplina de LDA.

A problematização manifesta-se devido à carência por uma plataforma direcionada para o ensino de construção de vocabulários controlados nas disciplinas de LDA, evidenciada por meio de levantamento de referências sobre os temas "Ciência da Informação" e "Representação da Informação", utilizando os termos: "Construction Thesaurus", associado com "Teaching tool', "Learning", "Software development" e "Mobile application", nas bases de dados do Portal de Periódicos da CAPES, SciELO e na Biblioteca Digital de Teses e Dissertações (BDTD). Os instrumentos da disciplina de LDA, antes feitos de forma manual ou híbrida, como os índices e cabeçalhos de assunto, necessitam deste aparato tecnológico para acompanhar a migração digital de forma a facilitar sua exemplificação, ensino, prática e aprendizagem, como no ensino da construção de tesauros sendo elemento essencial na organização do conhecimento em Representação da Informação.

Existem softwares especializados para a construção de tesauros como o TemaTres, o TermChoir e o TermTree, dentre outros disponíveis em sítios web, voltados para o uso profissional e acadêmico. (CAMPOS et al., 2006, p.78).

Dentre as metodologias para construção de tesauros, destacam-se as "Diretrizes para elaboração de tesauros monolíngues" (IBICT,1984), as "Diretrizes para o estabelecimento e desenvolvimento de tesauros monolíngues" (UNESCO, 1993), e as "Guidelines for the Construction, Format, and Managment of Monolingual Controlled Vocabularies" (ANSI/ NISO 39.19, 2010), que fomentaram junto com a análise e metodologias de autores como Cintra et al. (2002), Currás (1995), Dodebei (2002) dentre outros, o "Modelo Metodológico 
Integrado para Construção de Tesauro" de Cervantes (2009).

À vista disso, esta pesquisa tem como objetivo propor uma ferramenta digital, por meio de um aplicativo gamificado, para o ensino da disciplina de Linguagens Documentárias Alfabéticas.

\section{A DISCIPLINA DE LINGUAGEM DOCUMENTÁRIA NO ÂMBITO DA REPRESENTAÇÃO DA INFORMAÇÃO EM CIÊNCIA DA INFORMAÇÃO}

Os estudos em representação e recuperação da informação manifestaram-se na década de 1970, com a recuperação da informação em sistemas de informação, com o desafio de buscar a melhor forma de representar a informação pensando em sua otimização. Surgindo assim, os instrumentos de linguagens documentárias (LD) e os sistemas de classificação (ARAÚJO, 2014a). Porém antes disto, já havia reflexões sobre como se daria a separação do suporte físico de seu conteúdo.

Com esse desprendimento da materialidade, e a explosão da produção informacional surgiu a necessidade de pensar-se em como traduzir este conteúdo de forma a automatizar a recuperação da informação. Dando início, a disciplina de Recuperação da Informação, termo cunhado por Mooers (1951), chegando a ser considerada por muitos como o "núcleo" da Ciência da Informação (CI) (SARACEVIC, 1970).

A síntese de conceitos por Borko (1968) da Ciência da Informação figurase em um paradigma físico (CAPURRO, 2003), com foco nos meios e suportes tecnológicos para o processo de transmissão da informação sem direcionar o seu uso pelo usuário. Na década seguinte, Goffman (1970), acrescenta um novo elemento para ser levado em consideração no estudo deste fluxo informacional: a existência humana, ou seja, coloca o usuário dentro do processo.

Com esta percepção do ser humano como parte do processo, aprofundam-se os estudos em novas nuances e aplicações voltadas ao usuário, como as teorias cognitivas, estratégias de busca, as teorias de comunicação, os estudos de usuário, dentre outras. Salienta-se o segundo paradigma de Capurro (2003), o paradigma cognitivista, no qual se busca compreender a relação informação versus usuário, e em como ocorre o processo de assimilação para a 
construção do conhecimento. O terceiro paradigma de Capurro (2003) traz 0 aspecto social para dentro do campo da $\mathrm{Cl}$. Onde a informação passa a ser vista dentro de um contexto, por indivíduos e sua coletividade em seus mais variados ambientes. Esse paradigma, ainda se encontra em desenvolvimento na $\mathrm{Cl}$.

Saracevic (1996) redefine a Ciência da Informação ao encontro do terceiro paradigma de Capurro (2003), como um campo que se dedica a questões científicas voltadas para efetiva comunicação do conhecimento, no contexto social, no tratamento destas questões com o uso das tecnologias informacionais. Le Coadic (2004), afirma também a Ciência da Informação como uma ciência social. No decorrer do desenvolvimento da Ciência da Informação, subáreas foram delimitando-se, as quais de acordo com Araújo (2014b) são descritas como: a) Estudos de fluxo da informação científica e tecnológica; b) Estudos em representação e recuperação da informação; c) Estudos de usuário da informação; e f) Estudos métricos da informação.

Na subárea de estudos em representação e recuperação da informação, respaldando-se no primeiro paradigma de Capurro (2003), evidencia-se a preocupação com a automação do processo, na busca da criação de linguagens controladas e em seus indicadores de precisão e revocação que infere diretamente no número de documentos recuperados. Em seguida, são considerados os aspectos cognitivos dos usuários, tendo em conta suas necessidades de informação e sua linguagem de busca no uso do sistema de recuperação.

\subsection{Linguagem DocumentáRia: Conceito e Atributos}

Ao abordar sucintamente a $\mathrm{Cl}$ e a representação da informação, anteriormente, percebe-se como é forte a relação com a linguística. Afinal, para cumprir seu objetivo de recuperar a informação, é necessário utilizar das representações para tal. A linguagem em si, já é um tipo de representação, no qual representa o mundo das ideias, descreve a realidade, possibilitando assim a comunicação. E utilizando desse mesmo objetivo em comum, dentro da recuperação da informação, utiliza-se das Linguagens Documentárias para representar o conteúdo de um objeto em um sistema, de forma que ambas as 
vias, tanto máquina, quanto usuário compreenda a informação contida ali.

As LD, para Cintra et al. (2002), são utilizadas para a recuperação da informação. Essas linguagens são construídas para indexação, armazenamento e recuperação da informação e correspondem a sistemas de símbolos, destinadas a "traduzir" os conteúdos dos documentos, de uma linguagem natural para uma linguagem controlada, tornando possível a comunicação usuário/sistema. Devendo integrar três elementos básicos: Um léxico, uma lista de descritores pré-determinados e uma rede paradigmática que relacione os descritores uns com os outros, estabelecendo relações. São alguns exemplos de LD: cabeçalhos de assunto, os glossários, os dicionários, os vocabulários controlados, os sistemas de classificação decimal, as taxonomias, os tesauros e as ontologias.

A estrutura básica de uma LD é dada através das relações hierárquicas, que podem ser genéricas específicas ou partitivas, como no caso da CDD (Classificação Decimal de Dewey) e unidades que são relacionadas de forma não-hierárquicas, chamadas de "associativas". Ambas, apresentam relações de equivalência. Este gênero de relacionamento entre os termos é utilizado para permitir a entrada no sistema, operando no nível da sinonímia e da polissemia.

Como uma linguagem ela integra elementos léxicos, uma rede paradigmática, que os relacione, e uma rede sintagmática que os expresse, sendo sua estrutura básica as relações hierárquicas, que podem ser genéricas, específicas ou partitivas. E unidades que são relacionadas de forma não hierárquicas, chamadas de "associativas". Ambas, apresentando relações de equivalência. Este gênero de relacionamento entre os termos é utilizado para permitir a entrada no sistema, operando no nível da sinonímia e da polissemia. As relações hierárquicas podem ser exemplificadas pela CDD (Classificação Decimal de Dewey), no qual sua estrutura de 10 classes subordina outras classes, de conceitos macros para específicos. A fonte de referência para a construção das hierarquias é a estrutura teórico-conceitual de domínios específicos. Dentro das relações hierárquicas, temos as relações genéricas, em que partimos do geral ao específico.

Além das relações genéricas, podemos ter também, as relações partitivas, 
que expressa à relação entre o todo e suas partes. Como localidades geográficas, sistemas e órgãos do corpo. Já as relações não hierárquicas, apresentam relações do tipo causa/efeito, antes/depois, esquerda/direita, produtor/produto. Todos os conceitos podem se relacionar entre si em algum momento. Depois de estabelecido o sistema nocional, existe condições para propor relações entre os termos. Numa LD, não podem existir palavras que se refiram a um mesmo conceito ou uma palavra para designar vários conceitos. No caso da polissemia e ambiguidade, é necessário neutralizá-las, colocando, por exemplo, "qualificadores" para contextualizá-la. Ex.: Planta (Botânica), planta (Arquitetura), companhia (Empresa), companhia (Pessoa).

A sinonímia é a relação de equivalência entre ao menos duas palavras. A equivalência é um recurso normalizador importante para a compreensão de uma LD. Como atribuir como sinônimo, palavras populares a nomes científicos. Ex.: Gaivota/Larídeos, ou, Dor de cabeça/Cefaleia, Gilete/Lâmina de barbear, Garoto/Menino.

A hiponímia estabelece uma relação em vários níveis e sentidos. Como no caso a palavra "animal" que se relaciona com seus contrastes: vegetal, entre outros. No sentido de "mamífero" se contrapondo a aves, peixes. E no sentido de "bicho", que é oposto a seres humanos. Assim a palavra "animal" poderá surgir três vezes na classificação hierárquica da natureza.

A ligação lógico-hierárquica entre descritores é, no caso dos tesauros, mais clara, uma vez que é identificada pelos códigos TG (Termo Genérico ou Termo Geral), TE (Termo Específico) e nas relações não hierárquicas, TR (Termo Relacionado). Para relações de equivalência ou preferência de termos são utilizadas as expressões USE (Use) e UP (Usado Para) (CINTRA et al., 2002, p. 33).

\subsection{Modelo Metodológico para a Construção de Tesauro}

Cervantes (2009) em sua tese investiga a integração da Terminografia para a construção de Tesauros e realiza um estudo teórico e metodológico da construção de Tesauro em que apresenta um modelo metodológico para a construção de Tesauro com a integração de procedimentos terminográficos. 
Para a estruturação deste modelo, Cervantes (2009) realiza uma profunda pesquisa bibliográfica e diacrônica para mostrar a evolução dos conceitos de Tesauro, onde em síntese, na década de 1980, compreende-se que o tesauro é um vocabulário controlado, que se estrutura por meio de relações entre termos (IBICT, 1984; ISO 2788, 1986).

Na década de 1990, estabelece-se como uma linguagem documentária, dentro de um domínio do conhecimento para a representação de conteúdo dos documentos, e recuperação da informação, através da relação de seus termos por meio de associações, hierarquias ou equivalência (IBICT, 1984; VAN SLYPE, 1991; FUJITA, 1992; TÁLAMO; LARA; KOBASHI, 1992; UNESCO, 1993). A partir dos anos 2000, intensifica-se o seu uso como um instrumento terminológico-documentário para a tradução da linguagem natural, em uma linguagem documental, com rigoroso controle terminológico e com as relações sintático-semânticas (NAUMIS PEÑA, 2000; DODEBEI, 2002; ROBREDO, 2005; ANSI/NISO Z39.19, 2010).

Após este levantamento, Cervantes (2009), analisa algumas das normas mais relevantes para a construção de tesauros, sendo elas: as Diretrizes para elaboração de tesauros monolíngues, do Instituto Brasileiro de Informação em Ciência e Tecnologia (IBICT, 1984); as Diretrizes para o estabelecimento e desenvolvimento de Tesauros monolíngues (UNESCO, 1993); e as Guidelines for the construction, format and management of monolingual controlled vocabularies. (ANSI/NISO, 2010).

Sendo possível, após esta análise, agrupar em sete categorias temáticas as etapas de construção de tesauros: 1. Trabalho preliminar (orientações gerais); 2. Métodos de compilação; 3. Registro de termos; 4. Verificação de termos (Admissão e exclusão de termos); 5. Especificidade; 6. Uso de equipamento automático de processamento de dados; e 7. Forma e conteúdo de um tesauro. (CERVANTES, 2009, p. 103).

Além de compilar também, os métodos de construção e uso de recursos de informática para Tesauros, como os Tesauros de Ciência da Informação com uma lista alfabética e categorias de termos; o Tesauro Preliminar de Odontologia, que inovou no Brasil com sua aplicação automática de indexação de documentos 
e compilação de termos para construção de LDA; o Asis - Thesaurus of Information Science and Librarianship, que permite a construção de hierarquias e relacionamentos entre termos; e o Docutes - Tesauro de Ciências de la Documentación, que apresenta um conjunto de termos por facetas: Fontes de Informação, Representação e Recuperação da informação, entre outros. $E$, ainda, o Tesauro de Biblioteconomia y Documentacíon, criado para suprir a falta de léxicos em espanhol; o TCI - Tesauro em Ciência da Informação, que possui uma versão acadêmica; e o Thesaurus Construction System Version 8 (TCS-8) flexível para criação de tesauros e outros vocabulários. (CERVANTES, 2009).

A fim de integrar a metodologia da Terminologia à metodologia de construção de tesauros, a autora realiza uma revisão bibliográfica e apresenta o "Modelo Metodológico Integrado para Construção de Tesauro", que consiste em cinco etapas: 1. Trabalho preliminar, onde é feita a escolha do domínio e da língua do trabalho; a delimitação do subdomínio; limites da pesquisa terminológica e consulta ao especialista; 2 . Método de compilação com a coleta do corpus do trabalho terminológico; Estabelecimento da árvore de domínio; Expansão da representação do domínio escolhido; 3. Registro de termos, com sua coleta e classificação; 4. Verificação de termos, sua elaboração e relações de descritores e não descritores; e 5. Forma de apresentação do Tesauro (CERVANTES, 2009, p. 163).

A primeira etapa da construção de tesauros de Cervantes (2009) possui as seguintes especificações: a) Orientações gerais, em que se deve sinalizar à comunidade científica que um novo tesauro será construído, a fim de evitar a duplicação destes; b) Escolha da área de especialidade e da língua do tesauro: define-se aqui o idioma e a área de especialidade de encontro às necessidades dos usuários, além da abrangência e nível de especificidade; c) Delimitação de subárea de especialidade do tesauro, que consiste no nível de especificidade e tipo de usuário; d) Estabelecimento dos limites da pesquisa terminológica para áreas de especialidades: aqui deve-se limitar o número de termos a serem utilizados, sendo recomendado uma média de 300 termos como um levantamento básico e por volta de 2.500 termos para um levantamento exaustivo. Sendo esta decisão embasada nos recursos financeiros e 
disponibilidade de tempo. Recomenda-se aqui também, delimitar o número aproximado de descritores a serem incluídos no tesauro, em razão da rede nocional que the é própria e das redes nocionais conexas, para isso, utilizar o vocabulário de especialidade para as relações entre descritores; e e) Consulta a especialista da área/subárea de especialidade; ou seja, consultar especialistas na área de especialidade estabelecida para obtenção de validação do corpus representativo para a coleta de termos, bem como para conseguir 0 envolvimento do usuário (CERVANTES, 2009, p.165 - 166).

A segunda etapa do método de compilação é composta por: a) Abordagem de compilação, pois para uma maior flexibilidade da construção de um tesauro deve-se refletir sobre qual abordagem será utilizada. Sendo as mais enfatizadas, a indutiva, dedutiva e a combinação de métodos. Na combinação de métodos, é possível utilizar um método em um estágio e outro durante a construção. Podendo sempre ser revisadas para uma melhor consistência; b) Coleta do corpus para compilação de termos do tesauro: trata-se de reunir a documentação necessária para a compilação de termos do tesauro, como dicionários, vocabulários e tesauros de especialidade, normas terminológicas ou diretrizes indicadas por especialistas da área; Estabelecimento da estrutura conceitual/categorização, onde deve-se estabelecer a estrutura conceitual da área/subárea de especialidade em consonância com a documentação coletada anteriormente e consulta com os especialistas; e c) Expansão da representação da área de especialidade escolhida, decorrente da delimitação de subárea de especialidade e da estrutura conceitual/categorização, tornando-se necessário verificar os resultados obtidos para direcionar os trabalhos desta etapa (CERVANTES, 2009, p. 166 - 168).

A terceira etapa, registro de termos, constitui-se pela coleta e classificação de termos para construção do tesauro, que identifica os termos a serem extraídos da documentação, através de leitura no qual deve-se atentar a sua frequência, posição de destaque, como em títulos e estratégias discursivas, verificando se os termos pertencem a área de especialidade. Para o registro destes termos, deve-se utilizar uma ficha de termos que deve pontuar a identificação dos termos, seu contexto de uso, fonte, domínio de especialidade, 
definições e responsável pelo registro e data (CERVANTES, 2009, p. 168 - 169).

A quarta etapa é a de verificação de termos, no qual ocorre a verificação e classificação da noção/denominação, em que cada conceito/termo é reexaminado e analisado para adequações quando necessário, sendo analisado o seu conteúdo, sua posição na rede nocional da área de especialidade ou subárea. Buscando resultar numa delimitação mais precisa, numa classificação definitiva destes termos, bem como na rede de sinônimos através das remissivas para macro e microestrutura; e Notas de escopo ou de aplicação: deve-se apresentar aqui as instruções de uso para termos preferidos, bem como datas de inclusão/exclusão de descritores, funcionando como registro de realização de todas as etapas de construção de tesauro (CERVANTES, 2009, p. 169).

A quinta etapa, forma de apresentação de um tesauro, compõe-se por: a) Trabalhos de apresentação do tesauro, no qual se apresenta sistematicamente e alfabeticamente o tesauro. Sendo que, na apresentação sistemática, os descritores são relacionados conforme as categorias ou classes, dispostas em ordem alfabética. Na ordem alfabética, cada descritor ou não descritor aparece com aqueles que se relacionam, obedecendo a ordem: relação de equivalência, hierárquica (genérico e específico) e relações associativas (CERVANTES, 2009, p. 170). Conclui-se a construção do tesauro fundamentado no modelo metodológico integrado de Cervantes (2009).

Considera-se aqui o resultado do estudo da mestranda no estágio docente, realizado no âmbito do Programa de Pós-Graduação de Ciência da Informação na Universidade Federal do Ceará (PPGCI/UFC), na disciplina de LDA para a turma de $7^{\circ}$ semestre do curso de Bacharel em Biblioteconomia da UFC. Tendo como docente da disciplina e orientador da mestranda, o Professor Dr. Heliomar Cavati Sobrinho.

O plano de aula foi estruturado em três unidades, sendo a primeira a introdução a LD; a segunda com aprofundamento nos textos da bibliografia básica composta por Cintra et al. (2002), Currás (1995), Dodebei (2002), UNESCO (1993), Cavati Sobrinho (2014), dentre outros; e a terceira unidade, a construção orientada de um mini tesauro, utilizando-se da metodologia proposta por Cervantes (2009). 
A construção do mini tesauro ocorreu no laboratório de informática, dedicado aos estudantes do PPGCl, que após receber as orientações devidas, foi possível que, reunidos em dupla, construíssem um mini tesauro do domínio escolhido. Cabe destacar que, além da tese de Cervantes (2009), com as especificações, também se utilizou a tese de Cavati Sobrinho (2014), a qual analisa os termos de Economia dos Boletins de Conjuntura Econômica do Brasil e Linguagens Documentárias do domínio da Economia para propor a construção de um tesauro em Economia utilizando o modelo metodológico de Cervantes (2009).

\section{ENSINO E APRENDIZAGEM NO ÂMBITO DA BIBLIOTECONOMIA}

Diante das metodologias propostas para a construção de tesauros, é preciso refletir sobre como transmitir este conteúdo através do ensino de forma a acompanhar as atuais demandas da sociedade com a consequência vindas do uso das Tecnologias de Informação e Comunicação (TIC) e da sua interatividade proporcionada para o aprendizado substantivo em sala de aula.

Os futuros Bibliotecários que irão mediar a informação em seus mais variados suportes analógicos e/ou digitais necessitam conhecer e utilizar destas ferramentas da TIC desde a sua formação, uma vez que já a utilizam rotineiramente interagindo nas redes sociais e em outras plataformas digitais.

Por este motivo, o docente precisa ter os conhecimentos sobre novas formas de ensino-aprendizagem para optar pela mais adequada à realidade do ambiente educacional.

Farias (2015, p. 4) compila um conjunto de teorias de aprendizagem sendo as teorias inatistas, congênita ao sujeito; teorias ambientalistas que levam em consideração o meio no qual o indivíduo está inserido; teorias construtivas ou sócio interacionistas como um processo de interação entre sujeito e o objeto e as teorias cognitivistas, que se baseiam no pensamento lógico de modo a organizar e classificar as novas aquisições, atribuindo-Ihes significados.

Oliveira e Farias (2017) estudaram o perfil sociocultural e acadêmico dos alunos de Biblioteconomia da Universidade Federal do Ceará e em um dos pontos apresentados, averígua-se a consciência dos discentes quanto às suas 
responsabilidades na construção do conhecimento, resultando na concepção de uma maneira dialógica desta construção.

Tendo o diálogo ou a interação como elemento chave do processo de ensino-aprendizagem é importante trazer para reflexão a aprendizagem mecânica comumente utilizada e a Teoria de Aprendizagem significativa de David Ausubel (1968) pautada na visão cognitivista.

A aprendizagem mecânica é aquela puramente memorística que serve para testes e provas, sendo comumente esquecida a curto prazo, a conhecida "decoreba", tão utilizada por alunos, onde os conteúdos são listados de forma linear, sem conversarem entre si, sem idas e voltas. Sendo avaliados por provas, por certo ou errado.

$\mathrm{Na}$ Teoria da Aprendizagem Significativa de Ausubel (1968) o conhecimento prévio é o mais relevante na geração de novos conhecimentos e estabelece duas condições para a aprendizagem significativa: "1) o material de aprendizagem (livros, aulas, aplicativos) deve ser potencialmente significativo; e 2) o aprendiz deve apresentar uma predisposição para aprender" (MOREIRA, 2012, p.8).

Considera-se que a Teoria da Aprendizagem Significativa de Ausubel (1968) e que as dinâmicas atuais da sociedade demandam metodologias alternativas para o ensino-aprendizagem, como sugere-se aqui o uso da gamificação em conjunto com as TIC para uma potencialização e adaptação na construção de tesauros.

\section{GAMIFICAÇÃO NO ÂMBITO DA PLATAFORMA DIGITAL: CONCEITOS E METODOLOGIA}

Ao estudar o termo "gamificação", ou "gamification", encontram-se diversos conceitos, tanto de pesquisadores nacionais quanto internacionais que buscam defini-lo da melhor forma possível e comumente trazem os elementos dos jogos como seu cerne. No qual, estes elementos, tratam de uma ou mais características que podem ser comparadas a um jogo, como a representação do jogador por avatares, ambientes de realidade virtual, narrativa, feedback, ranking, regras de competição, formação de equipes, desafios, medalhas, dentre 
outros. (DETERDING et al., 2013 apud QUADROS, 2016, p. 35).

Estes elementos que caracterizam os jogos enquadram-se tanto nos jogos digitais como os não digitais. Segundo Quadros (2016), o termo "gamificação" surgiu em 1973, com Charles A. Coonradt, diretor de uma empresa de consultoria empresarial que é considerado o "avô da Gamificação", porém o termo só veio a ganhar força atualmente; além disso, existe controvérsia com relação a quem cunhou este termo, dado que Fadel et al, 2014, afirma que o precursor do termo foi Nick Pelling, um pesquisador britânico, em 2002.

Coonradt (1984) aplicava atividades recreativas ao local de trabalho, pois acreditava que elas promovem o aumento da produtividade e rentabilidade. Foi apenas após 2010, no entanto, que o termo gamificação se tornou amplamente adotado no sentido que as pessoas o usam agora como aplicação de estratégia de jogos a outras atividades. Como Scolari (2013) e Fadel et al (2014) que começaram a falar sobre o potencial dos elementos de games em contextos sociais como na educação e trabalho.

Fadel et al. (2014), acredita que a gamificação tem como razão de ser, cativar o indivíduo na realização de tarefas através de características dos jogos, pois associa-se a algo prazeroso, no qual propicia o engajamento do indivíduo e o motiva.

Diferente do jogo, o propósito da gamificação não é apenas de entretenimento. Busarello (2016) compreende gamificação como um sistema utilizado na resolução de problemas, por meio da elevação e manutenção dos níveis de engajamento, através do estímulo a motivação intrínseca do sujeito. Para isso, utiliza cenários lúdicos para simulação e exploração de fenômenos com objetivos extrínsecos, apoiados em elementos utilizados e criados em jogos. Tendo cinco variáveis que contemplam a gamificação: aprendizagem; mecânica de jogos; pensar como em jogos; motivação e engajamento; e narrativa.

Kevin Werbach e Dan Hunter (2012, apud QUADROS, 2016, p. 43) identificaram três tipos de elementos como categorias aplicáveis aos estudos e desenvolvimento da gamificação: as dinâmicas, as mecânicas e os componentes.

Sendo as dinâmicas os resultados relacionados aos comportamentos, 
interações e intenções dos jogadores que estão sendo incentivados pelos componentes e mecanismos, como as emoções, a narrativa, a progressão, relacionamentos e restrições. E as mecânicas, as ações essenciais para os componentes como a aquisição de recursos, desafios, recompensas, turnos e vitória. E os componentes são as ferramentas e abordagens que se relacionam com a finalidade do sistema, que podem ser usadas como os avatares, bens virtuais, coleções, conquistas, conteúdos desbloqueáveis, emblemas, níveis, pontos, presentes, ranking e os times.

Vianna et al. (2013) consideram que a gamificação abrange a utilização de mecanismos de jogos para a resolução de problemas e para a motivação e o engajamento de um determinado público. Para os autores, isso não significa, necessariamente, a participação em um jogo, mas a utilização dos elementos mais eficientes - como mecânicas, dinâmicas e estética - para reproduzir os mesmos benefícios alcançados com $\mathrm{o}$ ato de jogar e enumeram quatro características básicas que são próprias da mecânica dos jogos e essenciais para uma prática educativa da gamificação: metas, regras, sistema de feedback e participação voluntária.

\subsection{Plataformas Digitais e GamificaÇão para Aplicativos Móveis}

Qualquer ação executada na web requer um ambiente que agrupe seu código fonte e programação, e que por meio de uma interface, o usuário consiga navegar e executar suas atividades de forma autônoma e intuitiva. Esse ambiente constitui uma plataforma em meio digital. Estas plataformas digitais são muitas vezes complementadas pelas tecnologias digitais, como os dispositivos móveis em que as aplicações oferecem os mais variados produtos.

Gabriel (2010, p. 121) complementa essa definição elencando alguns tipos de plataformas e tecnologias digitais. As plataformas digitais abrangem as páginas digitais que se caracterizam por serem documentos HTML, interconectadas por meio de hipertextos e hiperlinks, sendo identificadas por URL e acessadas por navegadores.

Os dispositivos móveis surgiram na década de 1980, sendo seu precursor disponível para o comércio, o telefone celular Motorola DynaTAC 8000x que 
tinha como única função a de realizar ou receber chamadas. Atualmente com a incorporação a internet, é chamado de smarthphone (celular inteligente), que integram GPS (Global Positioning System), câmera fotográfica e vídeo, ferramentas utilitárias como calculadora, bloco de anotações, tocador de música, rádio, gravador de voz, agenda e potencializando ainda mais, os aplicativos para acesso a redes sociais, agências bancárias, gestão escolar, mobilidade nos transportes públicos, jogos, monitoramento de câmeras de vigilância e uma infinita gama de aplicações. As plataformas digitais mais acessadas para 0 download dessas aplicações, são o Google Play para dispositivos com sistema Android, e AppStore para sistemas iOs.

Lançado em 2008, com o nome Android Market, disponibilizava somente aplicativos para o sistema Android. Em 2012, integrando outras plataformas do Google, o Google Play passou a disponibilizar além de aplicativos, os jogos, filmes, programas de televisão, músicas e livros. E estes podem ser gratuitos ou pagos. Onde atualmente são disponibilizados 3,04 milhões de aplicativos mundiais.

É interessante apresentar aqui a evolução de produtos desta plataforma para dispositivos móveis desde o seu lançamento. O site Statista, realiza em tempo real este monitoramento, onde é possível visualizarmos a evolução de menos de 1 milhão de aplicativos em dezembro de 2009, para mais de 3 milhões de aplicativos, até setembro de 2020.

Este mesmo site, ainda complementa que a partir de fevereiro de 2020, os aplicativos Android de maior faturamento em todo o mundo incluíam aplicativos de jogos mais populares como o Pokemon Go e o Candy Crush Saga.

O que associado à pesquisa realizada pela Avazu (2020), empresa global especializada em publicidade, quanto ao uso de aplicativos no Brasil, explicita a utilização crescente dos dispositivos móveis e suas aplicações. Em suma, os resultados da pesquisa mostram que: O número de usuários de internet móvel no Brasil alcançou 135 milhões até maio de 2020; O sistema operacional mobile mais utilizado no Brasil é o Android, com 93,2\% dos usuários; o aplicativo móvel mais popular no Brasil é o WhatsApp, com 120 milhões de usuários; e a categoria de aplicativo mais popular no Brasil é a Social (WhatsApp, YouTube e 
Facebook).

\section{METODOLOGIA}

Este estudo foi desenvolvido por meio de procedimentos exploratórios e qualitativos. Utilizou-se a Análise de Conteúdo para exploração dos elementos da gamificação e sua categorização para o uso no desenvolvimento do protótipo do aplicativo gamificado para construção de tesauros.

Devido à forma como se manifesta esta pesquisa, através da vivência dos autores com o objeto pesquisado, e na busca de promover a interação deste com novos métodos educacionais e as ferramentas digitais, descreve-se esta pesquisa como de natureza qualitativa.

De caráter exploratório, pois objetiva propor a aplicação da gamificação de forma digital para construção de tesauros, no âmbito da Organização e Representação do Conhecimento no Brasil onde, até o momento, há carência de iniciativas deste teor.

Para a fundamentação e embasamento teórico desta pesquisa, dispôs-se da revisão bibliográfica de Lakatos e Marconi (2001, p. 183), que atribuem que esta coloca o pesquisador em contato direto com o que já foi produzido sobre determinado assunto. Contextualizando-se no cenário da sua área de pesquisa com autores, métodos e teorias.

Aplica-se a Análise de Conteúdo de Bardin (2011), que é "um conjunto de técnicas de análise das comunicações, que utiliza procedimentos sistemáticos e objetivos de descrição do conteúdo das mensagens" (BARDIN, 2011, p. 38). A qual se organiza em três fases: a) A pré-análise; b) A exploração do material; e, por fim, c) $O$ tratamento dos resultados: a inferência e a interpretação.

Na primeira etapa de pré-análise, organiza-se as ideias. É planejado o desenvolvimento das operações sucessivas. Definindo-se aqui os documentos a serem analisados, a formulação das hipóteses e objetivos, e a elaboração de indicadores que fundamentam a interpretação final (BARDIN, 2011, p. 95).

O roteiro do aplicativo foi construído com base no modelo metodológico de Cervantes (2009), e no modelo adaptado por Cavati Sobrinho (2014), aplicado à disciplina de LDA da Universidade Federal do Ceará, com o objetivo de adaptar 
esse modelo de construção de tesauros na construção da ferramenta digital, através de elementos da gamificação, elencando-se os elementos que mais correspondem ao processo de desenvolvimento do protótipo.

A segunda etapa, exploração do material, consiste em "operações de codificação, desconto ou enumeração, em função de regras previamente formuladas" (BARDIN, 2011, p. 101), sendo estas, as unidades (recorte), a escolha das regras de contagem (enumeração) e escolha das categorias (classificação e a agregação). Permitindo assim atingir uma representação do conteúdo.

$\mathrm{Na}$ terceira etapa, resultados obtidos e interpretação, onde os dados brutos são tratados de maneira a serem significativos, permitindo criar quadros, diagramas, e modelos, que no caso desta pesquisa é o desenvolvimento do aplicativo, no qual $\mathrm{o}$ analista pode vir a propor inferências e adiantar interpretações à luz dos objetivos previstos.

"Fazer uma análise temática, consiste em descobrir os 'núcleos de sentido' que compõem a comunicação e cuja presença, ou frequência de aparição pode significar alguma coisa para o objetivo analítico escolhido". (BARDIN, 2011, p. 105). Seguindo o passo a passo da análise de conteúdo de Bardin (2011), na fase de pré-análise, utilizando-se dos conceitos e elementos elencados pelos autores quanto a gamificação, elaborou-se uma síntese no qual se visualiza os principais elementos que o aplicativo móvel a ser desenvolvido necessita atender, onde através da análise desta, percebe-se que os elementos têm em comum algumas categorias gerais de temas que abrangem temas específicos. $O$ aspecto social do jogador engloba a necessidade de ostentar sua pontuação e ganhos para o outro, seu status no jogo, suas conquistas e bens virtuais que o motivam, engajam e o satisfaz. Sendo, a personalização, outro elemento, bastante importante, pois é o que identifica o jogador.

$\mathrm{Na}$ outra categoria, a estratégica, percebemos mais claramente os elementos dos jogos em si que são o cerne da gamificação, como as regras e missões. E a categoria de recursos, como as medalhas, conteúdos desbloqueáveis e pontos. Optou-se por atender aos seguintes elementos de cada categoria dos elementos da gamificação identificada: a) Social: a 
personalização de cada usuário através de um perfil com avatar e o compartilhamento de suas atividades no aplicativo na rede social Facebook. b) Estratégico e Recursos: Ranking de pontuação com os outros usuários do aplicativo através do sistema de pontos atribuídos a cada etapa concluída, para estimular o engajamento e a competição; c) e um tutorial para a explicação das regras e etapas. Sendo cada etapa do "jogo" correspondente ao "Modelo Metodológico Integrado para Construção de Tesauro" de Cervantes (2009).

\subsection{Prototipagem do Aplicativo Móvel}

A metodologia utilizada para o desenvolvimento do aplicativo móvel foi a prototipação. Segundo Pressman (2006, p. 42), a prototipação auxilia tanto ao desenvolvedor quanto ao usuário a entenderem o que realmente deve ser criado. As suas etapas compreendem: a) Comunicação entre o cliente, usuário e desenvolvedor para definir os objetivos; b) Plano rápido que é a representação do software através de rascunhos, mapas mentais ou wireframes; c) Construção do protótipo, com as telas clicáveis e o "esqueleto" do sistema em funcionamento para análise do cliente e teste; e d) Implantação, que após avaliado será criada a versão final, que não será comtemplada nesta pesquisa ficando para uma posterior continuidade. A seguir, apresenta-se a elaboração do protótipo do aplicativo gamificado para construção de tesauros.

\section{PROTÓTIPO DE APLICATIVO GAMIFICADO PARA CONSTRUÇÃO DE TESAUROS}

O desenvolvimento do protótipo do aplicativo segue as etapas de prototipação de Pressman (2006). Na primeira etapa, de comunicação, foi realizada uma reunião com um desenvolvedor analista em sistemas para que 0 mesmo compreendesse os elementos, o objetivo do aplicativo e o "Modelo Metodológico Integrado para Construção de Tesauro" de Cervantes (2009). Neste primeiro contato, o analista apresentou algumas dificuldades na compreensão de "tesauro", associando-o a um dicionário. Após esclarecimentos e analisar as possibilidades, o mesmo afirmou que era possível e que não tinha 
conhecimentos de programas semelhantes e que a parte mais difícil seria mesclar com a gamificação, mas que era viável. Assim, deu-se continuidade.

A segunda etapa, do plano rápido, resultou na representação e visualização das telas do aplicativo, em um desenho a mão com as ideias e os "caminhos" que o usuário teria que percorrer como, por exemplo: se o usuário clicasse no botão "Tutorial" como ele faria para sair do aplicativo, voltar para o menu principal ou dar continuidade? Esse rascunho foi aprimorado e sistematizado em um fluxograma.

A partir deste rascunho foi desenvolvido o design das telas e identidade visual do aplicativo no programa Adobe Photoshop por um design. Também houve com a design o momento de comunicação para explicação do projeto e objetivos. O aplicativo recebeu o nome de "Tabli" com a junção dos nomes "Tesauros" e "Biblioteconomia". A imagem escolhida para a logo consiste em uma coruja, símbolo da sabedoria e educação que comtempla um elemento da gamificação, funcionando como uma mascote que contribui para a ludicidade entre o aplicativo e o usuário, bem como a identidade visual.

A seguir, apresenta-se a esquematização do aplicativo e o percurso entre telas, ilustrado no fluxograma através de algumas telas já produzidas pelo design que ainda não foram em sua totalidade utilizadas no protótipo, devido ao curto prazo de tempo de desenvolvimento e justamente por ser um protótipo.

Ao acessar o aplicativo é apresentada a tela inicial de carregamento. Em seguida, surge a tela de acesso, onde o usuário possui duas opções: fazer 0 login através de seu e-mail e senha, caso o mesmo já esteja cadastrado, ou realizar o cadastro para poder acessar ao aplicativo. A tela de cadastro solicita os seguintes dados: nome completo, senha, confirmação de senha e o e-mail.

Após o login no aplicativo o usuário será encaminhado para seu perfil de usuário que contém seu avatar ou foto, nome, pontuação e os botões para "Tutorial" e "Construção de Tesauro", onde será realizado o jogo com as etapas metodológicas de Cervantes (2009). Nesta mesma tela ele poderá compartilhar seu desenvolvimento, nas etapas concluídas na rede social Facebook.

Na primeira opção do menu, o usuário, a qualquer momento, poderá consultar o Tutorial. Nesta tela do Tutorial, deverá conter tanto as orientações de 
como navegar pelo aplicativo, como também, remissivas para material bibliográfico de consulta como os de Cervantes (2009) e Cavati Sobrinho (2014). No botão de "Criar Tesauro" dentro do menu, são apresentados cinco botões que correspondem às cinco etapas metodológicas do "Modelo Metodológico Integrado para Construção de Tesauro" de Cervantes (2009): Escolha de domínio, Compilação, Registro de termos, Verificação de Termos e Apresentação de Tesauro.

$\mathrm{Na}$ escolha de domínio o usuário deverá escrever a área de domínio escolhida, o subdomínio como forma de delimitação da área do conhecimento a ser trabalhada e especificar a língua e número de termos a serem inseridos no tesauro. Nesta etapa, a pontuação será de acordo com o número de termos escolhido.

A próxima etapa consiste na compilação, que inicialmente foi planejada da seguinte forma: o usuário deveria anexar ao aplicativo até três documentos em formato $P D F$, sendo estes documentos os utilizados para a extração de termos, como livros, dicionários terminológicos e outros materiais que fomentem o subdomínio escolhido para que constem nas referências junto ao arquivo final da apresentação do tesauro. E a pontuação, seria de acordo com o quantitativo de arquivos anexados. Porém, esta etapa, no protótipo funcional, devido a sua complexidade de desenvolvimento, foi suprimida, ficando para um posterior desenvolvimento.

A etapa seguinte é a mais extensa, pois consiste no registro de termos um a um, com suas relações. E dependerá do número de termos indicado na tela de Escolha de Domínio. O usuário ao inserir um novo termo, deverá indicar as relações do mesmo com outros termos, podendo ser: Termo Geral (TG), Termo Específico (TE), Termo Relacionado (TR), Use (USE) e Usado Para (UP). Relações estas já apresentadas no Capítulo 2, para sinalização das relações no Tesauro através de notações.

Após os registros dos termos, o usuário poderá verificar cada termo para possíveis edições como excluir e alterar, tanto a sua grafia como a relação. $\mathrm{Na}$ última tela é possível visualizar toda a estrutura formada a partir do registro de termos e suas relações, sendo possível salvar o Tesauro em formato PDF ou 
$T X T$.

O desenvolvimento do protótipo funcional, com telas clicáveis e registro de termos, com a apresentação do tesauro foi elaborado com a utilização da linguagem de programação Java, que é de fácil implementação, gratuita e com grandes quantidades de bibliotecas OpenSource, de código aberto. É utilizada também, a linguagem de marcação XML (Extensible Markup Language) para a formatação do layout, definindo a posição, tamanho e altura dos componentes, assim como permite realizar a comunicação das classes com o layout e o SQLITE, um banco de dados, que permite seu funcionamento para o sistema android onde foi gerado um pacote em formato Android Application Pack (APK) que permite seu funcionamento e instalação em qualquer dispositivo móvel que utilize o sistema android.

Vale salientar que o código-fonte do aplicativo foi registrado no Instituto Nacional de Propriedade Intelectual (INPI), como Certificado de Registro de Programa de Computador, conforme processo №: BR512019001101-5.

Os próximos passos a partir deste protótipo será continuar seu desenvolvimento acrescentando as funcionalidades aqui planejadas e realizar as correções para que o mesmo venha a ter sua usabilidade testada com uma turma da disciplina de Linguagens Documentárias Alfabéticas no curso de Biblioteconomia da Universidade Federal do Ceará, para sua efetiva utilização, como, uma proposta de nova ferramenta educacional na construção de tesauros.

\section{CONSIDERAÇÕES FINAIS}

Esta pesquisa se desenvolveu tendo, como objetivo geral, propor uma ferramenta digital, por meio de um aplicativo gamificado, para o ensino da disciplina de Linguagens Documentárias Alfabéticas, o qual foi cumprido com a apresentação do protótipo funcional do aplicativo para dispositivos móveis nomeado de "Tabli". Em relação ao conteúdo utilizaram-se as cinco etapas da metodologia do "Modelo Metodológico Integrado para Construção de Tesauro" de Cervantes (2009) e os fundamentos da gamificação.

Concretizando, assim, o objetivo geral desta pesquisa, salienta-se a necessidade de continuar o desenvolvimento deste protótipo para agregar mais 
elementos e funcionalidades, adequando-o às fases de testes de usabilidade e de veiculação, para que, em breve, esta ferramenta seja uma realidade nas salas de aula, pois como visto na introdução deste trabalho há uma carência por ferramentas educacionais para a o ensino-aprendizagem em Representação da Informação, e a ausência de uma plataforma digital que atenda as atuais demandas de uso da tecnologia móvel.

Esse produto, ainda em fase embrionária, será de grande aplicabilidade tendo em vista que as dinâmicas atuais da sociedade demandam metodologias alternativas e, também, inclusivas, por meio da acessibilidade, para potencializar o ensino e aprendizagem na construção de tesauros, pois acreditamos que agregar o "Modelo Metodológico Integrado para Construção de Tesauro" de Cervantes (2009) à tecnologia móvel traga as vantagens de automação do processo, bem como a motivação e engajamento dos alunos, além de ser uma forma interativa e inovadora de aplicação para a área de Organização e Representação do Conhecimento.

\section{REFERÊNCIAS}

AVAZU. Disponível em: http://avazu.com/resources/whitepapers/. Acesso em: 07 out. 2020.

ANSI/NISO Z39.19-2005 (R2010). Guidelines for the Construction, Format, and Management of Monolingual Controlled Vocabularies. 2010. Disponível em: https://groups.niso.org/apps/group_public/download.php/12591/z39-192005r2010.pdf. Acesso em: 22 out. 2020.

ARAÚJO, C. A. Á. O que é Ciência da Informação?. Pesquisa Brasileira em Ciência da Informação e Biblioteconomia, n. 2, v. 9, 2014a. Disponível em: https://brapci.inf.br/index.php/res/v/28914. Acesso em: 22 out. 2020.

ARAÚJO, C. A. Á. Fundamentos da ciência da informação: correntes teóricas e o conceito da informação. Perspectivas em Gestão \& Conhecimento, João Pessoa, v. 4, n. 1, p.57-79, jan./jun. 2014b. Disponível em: http://periodicos.ufpb.br/index.php/pgc/article/view/19120. Acesso em: 26 jun. 2020.

AUSUBEL, D. P. Educational psychology: a cognitive view. New York: Holt,1968.

BARDIN, Laurence. Análise de conteúdo. São Paulo: Edições 70, 2011. 
BORKO, H. Information science: what is it? American Documentation, v.19, n.1, p. 3-5, 1968. Disponível em:

https://www.marilia.unesp.br/Home/Instituicao/Docentes/EdbertoFerneda/k--artigo-01.pdf. Acesso em: 26 jun. 2020.

BUSARELLO, R. I. Gamification: princípios e estratégias. São Paulo: Pimenta Cultural, 2016.

CAMPOS, Maria Luiza de Almeida; GOMES, Hagar Espanha; MARTINS, Alissandra Evangelista; CAMPOS, Maria Luiza Machado; CAMPOS, Linair Maria; SALES, Luana Farias. Perspect. ciênc. inf., Belo Horizonte, v. 11,n. 1,p. 68-81,Apr. 2006. Disponível em:

https://www.scielo.br/scielo.php?script=sci_arttext\&pid=S1413-

99362006000100006\&lng=en\&nrm=iso . Acesso em: 22 out. 2020.

CAPURRO, R. Epistemologia e Ciência da informação. In: ENCONTRO NACIONAL DE PESQUISA EM CIÊNCIA DA INFORMAÇÃO, 5., Belo Horizonte, 2003. Anais [...]. Belo Horizonte: Escola de Ciência da informação da UFMG, 2003. Disponível em: http://www.capurro.de/enancib_p.htm. Acesso em 31 mai. 2020.

CAVATI SOBRINHO, H. A representação documentária do domínio da Economia: análise de estruturas de representação em linguagens documentárias e documentos específicos de economia. Orientadora: Mariângela Spotti Lopes Fujita. 146f. Tese (Doutorado em Ciência da Informação) - Faculdade de Filosofia e Ciências, Universidade Estadual Paulista, Marília, 2014.149p. Disponível em: http://hdl.handle.net/11449/110390. Acesso em: 01 jun. 2020.

CERVANTES, B. M. N. A construção de tesauros com a integração de procedimentos terminográficos. Orientadora: Mariângela Spotti Lopes Fujita. 2009. 209f. Tese (Doutorado em Ciência da Informação) - Faculdade de Filosofia e Ciências, Universidade Estadual Paulista, Marília, 2009. Disponível em: https://www.marilia.unesp.br/Home/Pos-

Graduacao/Cienciadalnformacao/Dissertacoes/cervantes_bmn_do_mar.pdf. Acesso em: 31 mai. 2020.

CINTRA, A. M. M.; TÁLAMO, M. F. G. M.; GINEZ DE LARA, M. L.; KOBASHI, N. Y. Para entender as linguagens documentárias. São Paulo: Polis: APB, 2002. 96 p. Disponível em: http://abecin.org.br/e-books/colecao-palavrachave/CINTRA_et_al_Para_entender_as_linguagens_documentarias_2_ed.pdf. Acesso em: 26 jun. 2020.

COONRADT, C. Game of Work: How to enjoy as much as play. Liberty Press: Utah, 1984. 
CURRÁS, E. Tesauros: Linguagens terminológicas. Brasília: IBICT,1995. 286 p. Disponível em: https://livroaberto.ibict.br/handle/1/454 . Acesso em: 22 out. 2020.

DETERDING, S.; DIXON, D.; BIJÖRK, S.; LAWLEY, E.; NACKE; L. E. Designing Gamification: Creating Gameful and Playful Experiences. Extendes Abstracts, abr./maio, 2013. Disponível em: http://gamification-research.org/wpcontent/uploads/2013/03/20.Gamification_Extended_Abstract.pdf. Acesso em: 11 jul. 2020.

DODEBEI, Vera Lucia Doyle Louzada de Mattos. Tesauro: linguagem de representação da memória documentária. Niterói: Intertexto; Rio de Janeiro: Interciência, 2002. 119 p.

FADEL, L. M.; L. M.; ULBRICHT; V. R.; BATISTA, C. R.; VANZIN, T. Gamificação na educação. São Paulo: Pimenta Cultural, 2014. 300p. Disponível em: http://www.pgcl.uenf.br/arquivos/gamificacao_na_educacao_011120181605.pdf. Acesso em: 31 mai. 2020.

FARIAS, G. B. de. Teorias de aprendizagem aplicáveis ao ensino de biblioteconomia. REBECIN, v. 2, n. 2, p. 3-17, jul./dez. 2015. Disponível em: https://portal.abecin.org.br/rebecin/article/view/28. Acesso em: 24 ago. 2020.

FUJITA, M. S. L. Linguagem documentária em Odontologia: uma aplicação do sistema de indexação PRECIS. 1992. Tese (Doutorado em Ciências da Comunicação) - Escola de Comunicação e Artes, Universidade de São Paulo, São Paulo. 3v. Disponível em: https://www.marilia.unesp.br/Home/PosGraduacao/Cienciadalnformacao/Dissertacoes/fujita_msl_dr_mar.pdf . Acesso em: 22 out. 2020 .

GABRIEL, M. Marketing na era digital: conceitos, plataformas e estratégias. São Paulo: Novatec, 2010. Disponível em: https://kamilamendonca.files.wordpress.com/2015/09/marketing-na-eradigital.pdf. Acesso em: 31 mai. 2020.

GOFFMAN, W. Information science: discipline or disappearance. ASLIB Proceedings, v. 22 n.12, p. 589-596, 1970. Disponível em: https://www.emeraldinsight.com/doi/abs/10.1108/eb050268. Acesso em: 31 mai. 2018.

IBICT. Diretrizes para elaboração de tesauros monolíngües. Brasília, DF: IBICT, 1984. $70 \mathrm{p}$.

ISO 2788. Documentation - Guidelines for the establishment and development of monolingual thesauri. 1986. Disponível em: https://www.abntcatalogo.com.br/norma.aspx?|D=22202 . Acesso em: 22 out. 2020. 
LAKATOS, E. M.; MARCONI, M. A. Fundamentos metodologia científica. 4.ed. São Paulo: Atlas, 2001.

LE COADIC, Y. F. A ciência da informação. Brasília: Briquet de Lemos/Livros, 2004

MOOERS, C. N. Zatocoding applied to mechanical organization of knowledge. American Documentation, v. 2, n. 1, p.20-32, 1951.

MOREIRA, M. A. O que é afinal Aprendizagem significativa? Aula Inaugural do Programa de Pós-Graduação em Ensino de Ciências Naturais, Instituto de Física, Universidade Federal do Mato Grosso, Cuiabá, MT, 23 de abril de 2020. Aceito para publicação, Qurriculum, La Laguna, Espanha, 2012.

NAUMIS PEÑA, C. Análisis de la confluencia entre término y descriptor en la elaboración de tesauros. Investigación Bibliotecológica: archivonomía, bibliotecología e información. v.14, n. 29 jul./dic. 2000.

OLIVEIRA, M. J. de; FARIAS, G. B. Mediação bibliotecária no desenvolvimento de competências durante o estágio supervisionado. UFC: Foraleza, 2017. Disponível em: http://www.repositorio.ufc.br/handle/riufc/32179 . Acesso em: 22 out. 2020.

PRESSMAN, R. S. Engenharia de software. Rio de Janeiro: MeGraw-Hil, 2006. Disponível em: https://goo.gl/FkxhsN. Acesso em: 22 mai. 2020.

QUADROS, G. B. F. de. A gamificação no ensino de línguas online. 2016. $230 \mathrm{f}$. Tese (Doutorado em Letras) - Curso de Letras, Universidade Católica de Pelotas, Pelotas, 2016. Disponível em: https://wp.ufpel.edu.br/ppgl/files/2018/10/A-Gamifica\%C3\%A7\%C3\%A3o-noEnsino-de-L\%C3\%ADnguas-Online-Gerson-Bruno-Forgiarini-de-Quadros.pdf. Acesso em: 31 maio 2020.

ROBREDO, J. Documentação de hoje e de amanhã: uma abordagem revisitada e contemporânea da Ciência da Informação e de suas aplicações biblioteconômicas, documentárias, arquivísticas e museológicas. 4. ed. rev. e ampl. Brasília: Edição de autor, 2005.

SARACEVIC, T. Ciência da informação: origem, evolução e relações. Perspec. Ci. Inf., Belo Horizonte, v. 1, n. 1, p. 41-62, jan./jun. 1996. Disponível em: http://portaldeperiodicos.eci.ufmg.br/index.php/pci/article/view/235. Acesso em: 31 mai. 2020.

SARACEVIC, T. The concept of "relevance" in Information Science: an historical review. In: SARACEVIC, T.(ed.) Introduction to Information Science. New York: R. R. Bowker Co., 1970. p.11-154 
SCOLARI, C. A. HomoVideoludens 2.0. De Pacman a la gamification. Colleccio Transmedia XXI. Laboratori de Mitjans Interactius. Universitat de Barcelona.Barcelona, 2013.

TÁLAMO, M.; LARA, M.; KOBASHI, N. Contribuição da terminologia para a elaboração de tesauro. Ciência da Informação, Brasília, V.21, n.3, p.197-200, set./dez. 1992.

UNESCO. Diretrizes para o estabelecimento e desenvolvimento de tesauros monolíngües. [ $2^{\mathrm{a}}$ ed. rev. por Derek Austin e Peter Dale]; Trad. de Bianca Amaro de Melo; rev. de Lígia Maria Café de Miranda. Brasília: IBICT; SENAI, 1993.

VAN SLYPE, G. Lenguages de indización: concepción, contrucción y utilización en los sistemas documentales. Trad. Pedro Hípola e Félix de Moya. Madrid: Fundación Germán Sánchez Ruipérez, 1991.

VIANNA, Y.; VIANNA, M.; MEDINA, B; TANAKA, S. Gamification, Inc.: como reinventar empresas a partir de jogos. Rio de Janeiro: MJV, 2013. Disponível em: http://www.gestaoporprocessos.com.br/wpcontent/uploads/2014/06/Gamification-Inc-MJV.pdf. Acesso em 31 mai. 2020.

WERBACH, K.; HUNTER, D. For the win:How game thinking can revolutionize your business. Wharton Digital Press: Philadelphia, 2012.

\title{
TABLI: PROTOTYPING OF A GAME APPLICATION TO THE THESAURUS CONSTRUCTION
}

\begin{abstract}
Introduction: This research aims to present the use of digital tecnologies and gamification in the subject Documentary Languages (DL), due to the lack of a platform towards the teaching of vocabulary construction in this subject that goes through reality using Education technologies as learning tools. Due to the current characteristics of students with the use of mobile platforms, gamification in educational digital environments makes the process interactive, intuitive and motivating for their methodological strategies. Objective: To propose a digital tool, using a gaming applicative to teach the subject of DL. Methodology: Uses the "Integrated methodological model for thesaurus construction" (CERVANTES, 2009), Content Analysis (BARDIN, 2011) for the elements of gamification and prototyping (PRESSMAN, 2006) for the construction of the application prototype. Result: Development of the prototype application named "Tabli" with gamification elements for thesaurus construction. Conclusion: There is a need to continue the development of the "Tabli" application, which could be useful to the current dynamics of society that demand both alternative and inclusive methodologies through accessibility, to enhance teaching and learning in the thesaurus construction, because it is believed that adding the Cervantes (2009) model to mobile technology brings the advantages of process automation, as well as the motivation and engagement of students, in addition to being an interactive and innovative form of application for the area of Knowledge Organization and
\end{abstract}


Representation.

Descriptors: Representation of information. Thesaurus construction. Information technology. Mobile applications. Gamification. Digital platforms.

\title{
TABLI: PROTOTIPO DE APLICACIÓN GAMIFICADO PARA CONSTRUCCIÓN DE TESAUROS
}

\begin{abstract}
RESUMEN
Introducción: Esta investigación presenta como tema la utilización de tecnologías digitales y de la gamificación en la disciplina de Lenguajes Documentales (LD), debido a la falta de una plataforma específica para la enseñanza de construcción de vocabulário, en esta disciplina, que se adapte a la realidad con el uso de tecnologías educativas como herramientas para el aprendizaje, y debido a las características actuales de los estudiantes con el uso de las plataformas móviles, la gamificación en entornos digitales educativos hace que el proceso sea interactivo, intuitivo y motivador por sus estrategias metodológicas. Objetivo: Proponer una herramienta digital, a través de una aplicación gamificada, para la enseñanza de la disciplina LD. Metodología: Utiliza el "Modelo metodológico integrado para la construcción de tesauros" (CERVANTES, 2009), análisis de contenido (BARDIN, 2011) para los elementos de gamificación y prototipos (PRESSMAN, 2006) para la construcción del prototipo de aplicación móvile. Resultado: Desarrollo del prototipo de la aplicación denominada "Tabli" con elementos de la gamificación para la construcción de tesauro. Conclusión: Es necesario continuar con el desarrollo de la aplicación "Tabli", para que se puede aplicar a las dinámicas actuales de la sociedad que demandan metodologías alternativas y también inclusivas, a través de la accesibilidad, para potenciar la enseñanza y el aprendizaje en la construcción de tesauros., porque se cree que la incorporación del modelo Cervantes (2009) a la tecnología móvil aporta las ventajas de automatización del proceso, así como la motivación y el compromiso de los estudiantes, además de ser una aplicación interactiva e innovadora para la Organización y Representación del conocimiento.
\end{abstract}

Descriptores: Representación de información. Construcción de tesauros. Tecnología de la información. Aplicaciones móviles. Gamificación. Plataformas digitales.

Recebido em: 15/09/2020

Aceito em: 30/09/2020 